\title{
Como aprendem estudantes universitários? Estudo de caso sobre estratégias e estilos de aprendizagem
}

\author{
How university students learn? Case study about \\ strategies and styles of learning \\ ¿Cómo aprenden los estudiantes universitarios? Estudio \\ de caso sobre estrategias y estilos de aprendizaje \\ MÁRCIA MINEIRO ida \\ CRISTINA D'ÁVILA id b
}

\section{Resumo}

O artigo tem como temática central os estilos de aprendizagem em contexto universitário. Objetivou-se em âmbito geral: Analisar compreensivamente as estratégias de aprendizagem referidas por discentes de um curso de Ciências Contábeis, em uma Universidade pública na Bahia, inferindo sobre seus estilos de aprendizagem preferenciais. Como objetivos específicos, pretende-se levantar as estratégias de aprendizagem prevalentes e inferir sobre os estilos de aprendizagem prevalentes dos alunos. Crê-se que ao atingir os objetivos, o material produzido pode servir de auxílio às escolhas inerentes à mediação didática em contexto universitário com vistas a uma docência emancipadora. Buscou-se apoio na literatura concernente aos estilos de aprendizagem que mantém congruência com aprendizagem de adultos, bem como com a teoria da aprendizagem significativa. A investigação é de abordagem qualitativa,

\footnotetext{
a Universidade Estadual do Sudoeste da Bahia (UESB), Vitória da Conquista, BA, Brasil. Mestre em Contabilidade, e-mail: periciacontroladoria@yahoo.com.br

${ }^{\mathrm{b}}$ Universidade Federal da Bahia (UFBA), Salvador, BA, Brasil. Doutora em Educação, e-mail: cmdt@ufba.br
} 
interpretativa, adotando-se como método procedimental um estudo de caso único instrumental. Utilizou-se questionário misto eletrônico e grupo focal para a produção dos dados, examinados mediante a análise de conteúdo de orientação francesa com categorias a posteriori. Encontraram-se estratégias prevalentes, as quais estando congruentes com os variados estilos subjetivos de aprendizagem, ao longo da vida acadêmica dos discentes pesquisados, podem fomentar melhores condições para aprender e atuar assertivamente na sociedade. Concluiuse, ainda, que o aspecto socioemocional influencia nos estilos de aprendizagem e suas preferências.

Palavras-chave: Aprendizagem. Estilos de aprendizagem. Educação Superior.

\section{Abstract}

This article has as central subject the learning styles in higher educational context. Its main objective is to analyse comprehensively the learning strategies referred by accounting students in a Public University in Bahia inferring about their preferential learning styles. It has as specific objectives to identify the preferential strategies and to infer about the students prevalent learning styles. It is believed that the material produced after reaching the objectives can serve as an aid to inherent didactic mediation's choices aiming an emancipatory teaching in a university context. It is supported by the literature concerned with learning styles, which is consistent with adult learning, as well as significant learning theory. The research has a qualitative interpretative approach, adopting as a procedural method a single instrumental case study. A mixed electronic questionnaire and focus group were used for the data's production that were analyzed by French content analysis with posteriori categories. It was found the prevalent strategies, which being congruent with the varied subjective learning styles throughout the academic life of the researched students may foster better conditions to learn and act assertively in society, it was also concluded that the social-emotional aspect influences the learning styles and in their preferences.

Keywords: Learning. Learning styles. Higher education.

\section{Resumen}

El artículo tiene como temática central los estilos de aprendizaje en contexto universitario. El objetivo en ámbito general es: analizar comprehensivamente las estrategias de aprendizaje referidas por alumnos de un curso de Ciencias Contables, en una universidad pública en Bahia, infiriéndose sobre sus estilos de aprendizaje preferenciales. Como objetivos específicos, se pretende identificar las estrategias de aprendizaje prevalentes e inferir sobre los estilos de aprendizaje prevalentes de los alumnos. Se cree que al atender a los retos, el material producido puede servir de ayuda a las escojas inherentes a la mediación didáctica en contexto universitario objetivando una docencia emancipadora. Se buscó apoyo en la literatura concerniente 
a los estilos de aprendizaje que mantienen congruencia con el aprendizaje de adultos, y también con la teoría del aprendizaje significativo. La investigación es de abordaje cualitativa, interpretativa, adoptándose como método procedimental un estudio de caso único instrumental. Se utilizó cuestionario mezclado electrónico y grupo focal para la producción de datos, analizados según el análisis de contenido de orientación francesa con categorías posteriores. Se encontraron estrategias prevalentes, las cuales siendo congruentes con los variados estilos subjetivos de aprendizaje a lo largo de la vida académica de los estudiantes investigados pueden fomentar mejores condiciones para aprender y actuar asertivamente en sociedad, aún se concluyó que el aspecto socioemocional influye en los estilos de aprendizaje y sus preferencias.

Palabras clave: Aprendizaje. Estilos de aprendizaje. Educación Superior.

\section{Introdução}

Como um médico pode auxiliar um paciente na cura de uma enfermidade? Entre outras coisas, primeiramente ele precisará conhecer como funciona a doença, seus mecanismos de ação, seus sintomas e recursos medicamentosos que combatam as formas de instalação do processo enfermiço e seus efeitos. Ou seja, conhecendo como a doença funciona o médico pode atuar melhor. E como o professor pode auxiliar um aluno a aprender? Entre outras coisas, primeiramente ele precisará conhecer como funciona a aprendizagem, seus mecanismos de ação, suas características e recursos didáticos que propiciem a instalação do processo de aprendizagem e seus detalhamentos. Ou seja, conhecendo como a aprendizagem funciona, o professor pode atuar melhor.

Pedindo a devida licença para iniciar por meio dessa analogia, este trabalho se propõe a uma aproximação do processo de aprendizagem no sentido de melhor conhecer seu funcionamento, resultando em uma possível melhoria na atuação docente. O médico intervém dispondo conhecimentos, protocolos, terapias e recursos medicamentosos (ação médica) para que a cura (ação conjugada entre esforços do paciente, medicamento e reação do organismo) seja desencadeada. De semelhante forma, o professor intervém dispondo de conhecimentos técnicos, pedagógicos, didáticos e sensíveis, bem como, recursos didático-metodológicos (mediação didática) para que a aprendizagem (Mediação 
cognitiva - relação entre a estrutura cognitivo-afetiva do indivíduo e o objeto do conhecimento) seja desencadeada (D'ÁVILA, 2013).

Crê-se que conhecer o processo de aprendizagem dos estudantes "facilita identificar e elaborar estratégias de ensino mais adequadas" (CASTRO, 2007, p. 11, tradução nossa) para cada forma de aprender. Pois, também se acredita que cada indivíduo é dotado de suas subjetividades, as quais se expressam também sob diferentes formas para captar, processar e utilizar as informações, ou seja, as pessoas possuem diferentes estilos de aprendizagem.

Um levantamento exploratório sobre a aprendizagem, suas teorias e seus estilos fornece um leque teórico muito amplo, para tratar dessa temática é preciso decidir em que se deve enfocar como estudo e fazer recortes literários, assumindo que há diversas vertentes e que um artigo científico, mesmo construído com o maior cuidado e rigor, não consegue abarcá-las em completude.

Selecionaram-se, então, como sustentáculos teóricos Ausubel (2009) com a Teoria da Aprendizagem Significativa; Kolb (1984) com a teoria da aprendizagem pela experiência e os estilos de aprendizagem; Dunn e Dunn (1979) com os estímulos de aprendizagem; A teoria VARK criada por Neil Fleming e Colleen Mills (1992) e Os estilos de aprendizagem segundo Alonso, Gallego e Honey (2007), por acreditar que, embora não combinem entre si, essas teorias aportam explicações sobre a aprendizagem de adultos.

Já que os estilos são levantados mediante diversos instrumentos e conforme teorias diferentes, complementares em muitos casos, não havendo consenso, e não concordando com padronizações — que no fundo resultam ser classificatórias e excludentes, ou mesmo estarem postas a serviço de treinamentos empresariais, ou outras lógicas neoliberais inseridas na Educação Superior - optou-se por reconhecer os estilos de aprendizagens mediante as estratégias concretamente utilizadas pelos discentes, segundo eles mesmos.

Ou seja, buscou-se como objetivo geral neste artigo analisar compreensivamente as estratégias de aprendizagem referidas por discentes de um curso de Ciências Contábeis, em uma Universidade pública na Babia, inferindo sobre seus estilos de aprendizagem preferenciais. Já como objetivos específicos buscou-se levantar as estratégias de aprendizagens prevalentes, e inferir sobre os estilos de aprendizagem prevalentes dos alunos. 
Acredita-se que os achados dessa investigação poderão colaborar com docentes que ressignificam sua prática e fazem da educação continuada seu caminho para a práxis emancipadora, pois as depreensões encontradas sobre a aprendizagem discente podem servir de auxílio às escolhas inerentes à mediação didática, em especial na Educação Superior.

Empreendeu-se uma investigação alicerçada na abordagem paradigmática qualitativa, com objetivos interpretativos. Tratou-se de uma bricolagem entre um estudo de caso único instrumental e esparsas inserções de relato de experiência. A pesquisa delimita-se a uma universidade pública estadual no curso de Ciências Contábeis, junto aos discentes a partir do $5^{\circ}$ semestre. Utilizou-se questionário misto eletrônico e grupo focal para a produção dos dados, que foram analisados mediante a análise de conteúdo francesa com categorias a posteriori.

No intuito de melhor organizar este artigo ele foi composto por três partes: esta introdução (contendo apresentação temática, fonte teórica, delimitações objetivos, justificativa, resumo metodológico e visão geral), pelo desenvolvimento (no qual há síntese teórica, detalhamento metodológico e análise de dados), pelas considerações finais (sintetizando teoria, objetivos, métodos, achados e sugestões) além das referências empregadas.

\section{Desenvolvimento}

Por princípio, a aprendizagem é um processo sequencial, vitalício, que envolve habilidades e atitudes que podem ser potencializadas e desenvolvidas, tem aspecto individual e social: no primeiro caso ao considerar diferenças de preferências na forma de aprender e conjunto de necessidades; no segundo caso considerando os grupos, as informações disponíveis, a cultura, o contexto histórico, as situações e as oportunidades (MUNFORD, 2001).

Com o intuito de compreender como se dá a aprendizagem individualmente, alguns estudiosos categorizaram as aprendizagens segundo a forma que cada pessoa aprende, levando em conta os estímulos de maior influência, a personalidade e os canais de percepção que mais facilitam o acesso e a apreensão da informação. 
Os estudos ao longo dos anos mostraram uma prolífica e diversificada categorização, esta que, segundo Portilho (2005), retrata a coexistência de concepções variadas sobre o processo de aprendizagem e uma dificuldade de consenso entre elas, entretanto trazem algumas coisas em comum: os traços de personalidade apontam diferenças nos estímulos preferenciais e canais para aceder à informação, visando aprender da maneira mais eficaz possível, pois cada indivíduo aprende diferentemente, em ritmo próprio e conforme suas preferências.

É de grande valia, nesse âmbito de estudos, o reconhecimento de alguns princípios dos estilos de aprendizagem, como leciona Rodríguez (2008), em especial que "as pessoas têm perfis (ou padrões) de estilo, não um só estilo" e que "os estilos são variáveis de acordo com as tarefas e as situações" (RODRÍGUEZ, 2008, p. 20, tradução nossa). Estes princípios ratificam que há gradações e flexibilidades nos estilos e nas subjetividades ligadas à aprendizagem.

Isso depura o caráter "rotulador", "padronizador", classificatório, excludente (?) que os estudos sobre estilos de aprendizagem costumam ganhar quando caem nas mãos que desejam maximizar resultados e minimizar recursos a todo custo. Tais princípios reafirmam que os indivíduos são singulares, tal como seus processos idiossincráticos de aprendizagem, uma verdadeira bricolagem de estratégias, canais de acesso à informação, maneira de percepção e processamento dela.

Reuniram-se na Figura 1 os nomes de alguns dos pesquisadores dos estilos de aprendizagem, o ano de suas publicações mais impactantes, bem como o que dizem seus estudos, os quais ficaram conhecidos genericamente de pesquisas sobre os Estilos de Aprendizagem entendidos como as "características do comportamento que indicam como a pessoa aprende e se adapta a partir do ambiente em que está inserida” (GREGORC, 1979 apud SCHMITT; DOMINGUES, 2016, p. 363). 
Figura 1 - Pesquisas sobre estilos de aprendizagem

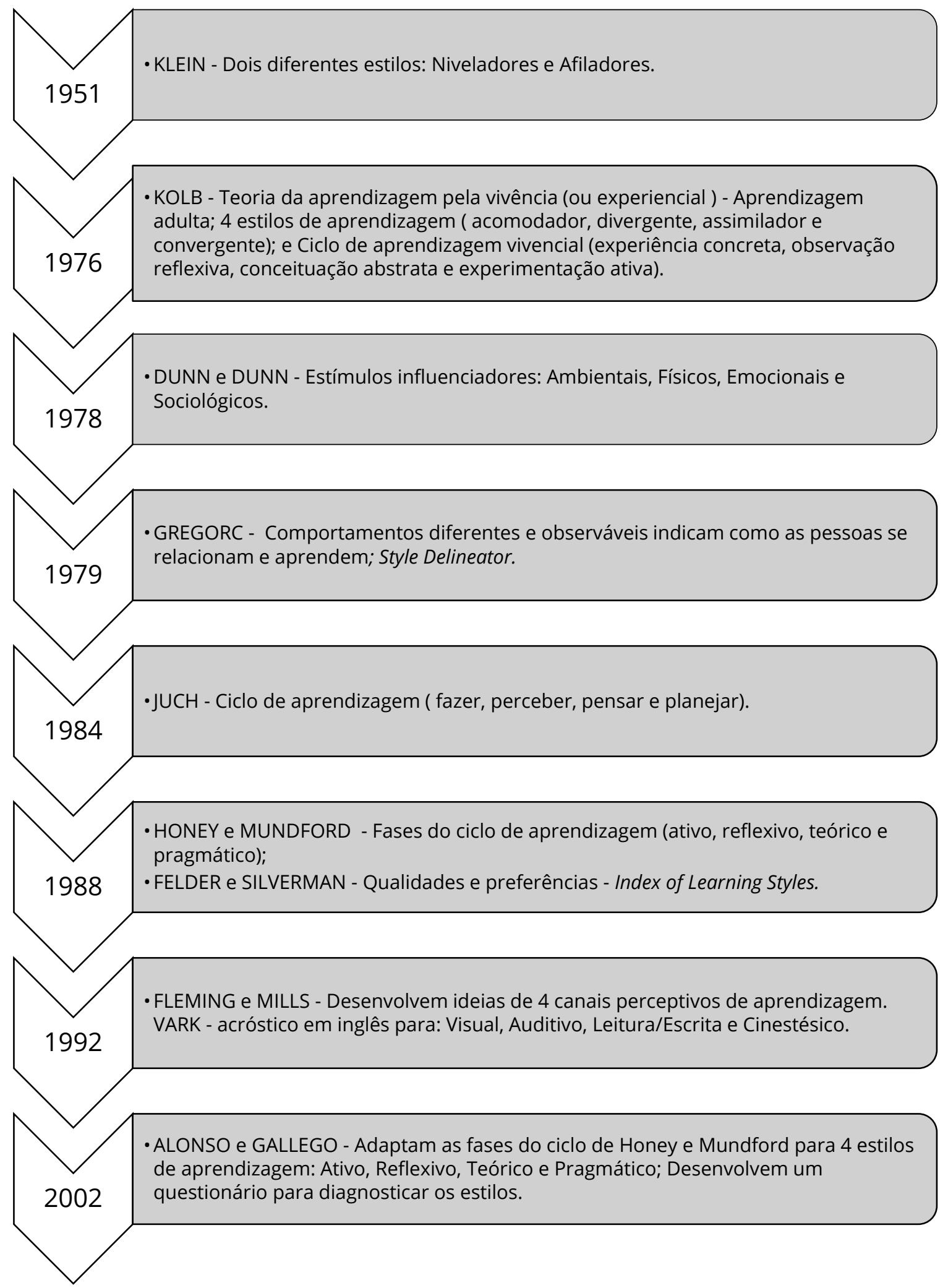

Fonte: Elaboração própria com base em Barros (2008, p. 15-19) e Schmitt e Domingues (2016, p. 372-376). 
Barros (2008) revisa amplamente as teorias dos estilos de aprendizagem e informa que estes são as maneiras individuais e subjetivas de processar a informação conforme os sentimentos e os comportamentos nas situações de aprendizagem influenciando a maneira de aprender um conteúdo. São mais flexíveis e sujeitos a mudanças ao longo da vida, pois levam em conta traços psicológicos, afetivos, cognitivos, fisiológicos e até sociológicos. Diferindo dos estilos cognitivos, os quais são mais estáveis e se referem à maneira de processar informações, recordá-las e pensá-las para solucionar problemas.

Reconhecer as predominâncias de estilos de aprendizagens equipa o professor com o conhecimento sobre como pode melhor lastrar sua mediação didática em recursos, dispositivos e atividades, estas que intensifiquem capacidades e favoreçam a relação de ensino e aprendizagem. Aliás, essa foi uma das conclusões da pesquisa empreendida por Portilho (2005), indicando haver uma necessidade de que o professor não só conheça como seus alunos aprendem, mas também como ele mesmo aprende "visando a melhoria do processo ensino-aprendizagem" (PORTILHO, 2005, p. 14, tradução nossa).

Não se trata de rotular os alunos, mas sim de escolher melhor as possibilidades metodológicas para o tratamento dos conteúdos e desta forma tentar atender, dentro do possível, às individualidades no contexto áulico. Isso também auxilia o aluno, que sabendo quais são suas propensões e aptidões para aprender, pode: incrementar seus canais e estímulos preferidos, desenvolver os outros canais e minimizar a influência de estímulos que lhe são negativos.

No entender de Jacobson (2003 apud SCHMITT'T DOMINGUES, 2016) conhecer os vários estilos de aprendizagem presentes na sala de aula favorecem o planejamento da mediação didática docente, no sentido de contemplar a maioria delas mediante uma variedade e flexibilidade metodológica. "Quando ensinados através de métodos que complementam suas características de aprendizagem, alunos de todos os níveis se tornam progressivamente mais motivados e alcançam mais sucesso acadêmico" (DUNN; DUNN, 1979, p. 239, tradução nossa). Aqui, sucesso é compreendido como a emancipação intelectual do indivíduo.

Assim, conhecer seu próprio estilo de aprendizagem possibilita “à pessoa conscientizar-se de seu estilo atual de assimilar o conhecimento, observando e 
analisando quais são os mecanismos que utiliza para aprender o que já aprendeu e o que falta para aprender" (PORTILHO, 2005, p. 14, tradução nossa).

Explorando, ainda que en passant, as teorias dos estilos de aprendizagens, optou-se por levantar algumas informações sobre as ideias de Kolb (por ter declaradamente o enfoque na aprendizagem de adultos), Dunn e Dunn, Fleming e Mills e Alonso, Gallego e Honey por serem os mais conhecidos, em função de terem criado (e testado) instrumentos/questionários para diagnóstico dos estilos, ainda que sejam díspares entre seus elementos teóricos.

A teoria da aprendizagem pela experiência (ou experiencial ou, ainda, vivencial — dependendo da tradução) é uma "perspectiva holística e integrativa de aprendizagem que combina experiência, percepção, cognição e comportamento" (KOLB, 1984, p. 21, tradução nossa). Alcançou boa inserção no "mundo corporativo" 1 por enfocar a aprendizagem do adulto. Para elaborar sua teoria, Kolb considerou o relacionamento entre: trabalho, aprendizagem, atividades cotidianas e a construção de conhecimentos. Sustentou-se em ideias de Dewey, Lewin, Piaget e Freire (sobre a educação bancária) para indicar que o centro do processo de aprendizagem está na experiência/ na vivência. Segundo Kolb (1984) a observação e a ação são processos simbióticos e o feedback é o elemento para a efetividade dos processos.

São pressupostos da aprendizagem pela vivência que: a aprendizagem é melhor concebida como um processo, não em termos de resultados; a aprendizagem é um processo contínuo baseado na experiência; a aprendizagem é um processo holístico de adaptação ao mundo; a aprendizagem envolve transações entre a pessoa e o ambiente; a aprendizagem é o processo de construir conhecimento.

Kolb, para elencar seus quatro estilos de aprendizagem, cruzou tipos opostos de percepção (concreta e abstrata) da informação (cf. Figura 2 eixo vertical) com tipos opostos de processamento da informação (ativo e reflexivo - eixo horizontal), resultando em quatro quadrantes que permitem gradações entre si.

\footnotetext{
1 Ainda que esteja claro e expresso, na obra de 1984, que seus supostos são construtivistas e humanistas, os estudos de Kolb são tomados emprestado para aprendizagem em organizações com intuitos behavioristas de aprendizagem no trabalho - "treinamento" (adestramento?) de funcionários. Como exemplo, cf. Mumford (2001). Dessa maneira, há que se depurar as concepções utilitaristas e excludentes que a teoria de Kolb possa trazer para estudá-la adequadamente à luz de supostos emancipatórios.
} 
Figura 2 - Os estilos de aprendizagem de Kolb

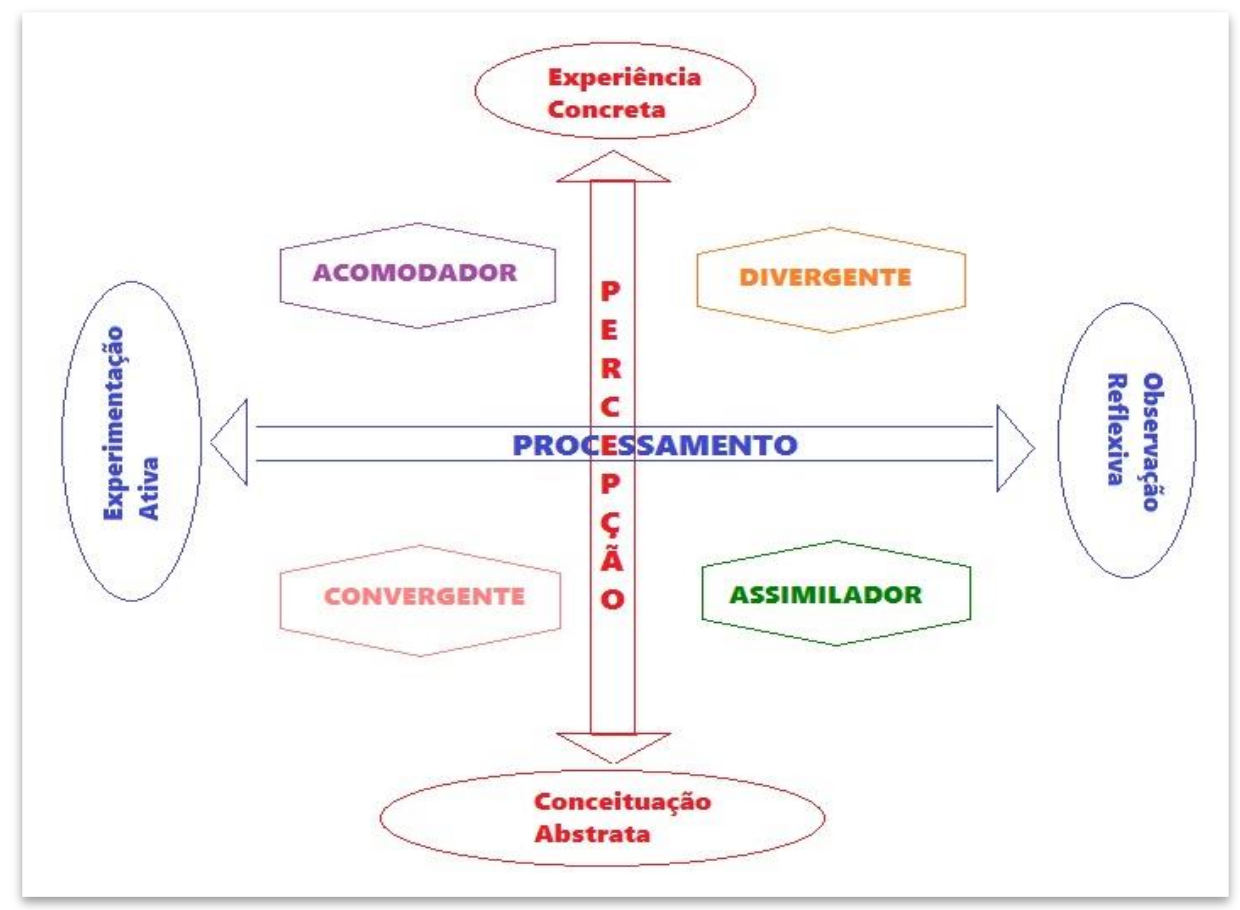

Fonte: Elaboração própria com base em Kolb e Kolb (2005); Kolb, Rubin e Mclntyre (1978) e Jericó (2016).

Para Kolb e Kolb (2005) pode-se inventariar, por meio de testes, os estilos de aprendizagem em: Acomodador/Adaptador (o "especialista em fazer fazendo" pessoas que aprendem por tentativa e erro, assumem riscos, não se prendem a detalhes nem a teorias, são movidos por multiplicidade e pela ação. Sua pergunta característica é “quando?”); Divergente (o “especialista em mil ideias criativas” — Aprendem experimentando, analisam globalmente, gostam de trabalhar com pessoas, são espirituosos e empáticos. Sua pergunta característica é "e se...?” ou "por que não?”); Assimilador (o "especialista em conceituar" — criam modelos teóricos, aprendem refletindo e observando, definem problemas e têm pensamento abstrato. Sua pergunta característica é “por que?”); e Convergente (o “especialista em uma coisa por vez" - aprendem fazendo, precisam de aplicação prática, se perdem em meio a muitas opções. Sua pergunta característica é “Para quê?”) (JERICÓ, 2016).

Rita Dunn e Kenneth Dunn, no final da década de 1970, desenvolvem suas ideias sobre os estilos de aprendizagem buscando como agir para minimizar insucessos acadêmicos e como agir com os alunos desmotivados (segundo eles, são aqueles não persistentes e menos autônomos/responsáveis), dizem que a mediação 
didática nestes casos requer "tarefas mais curtas ou muito poucos objetivos, frequente feedback, um grande trabalho de supervisão e elogios autênticos enquanto eles estão trabalhando" (DUNN; DUNN, 1979, p. 239, tradução nossa). Os estilos de aprendizagens segundo os estímulos — condensados em um mapa mental (Figura 3) - foram convertidos em um teste para avaliar os elementos que interferem na aprendizagem, aos moldes de um inventário.

Figura 3 - Mapa mental sobre os estímulos de aprendizagem

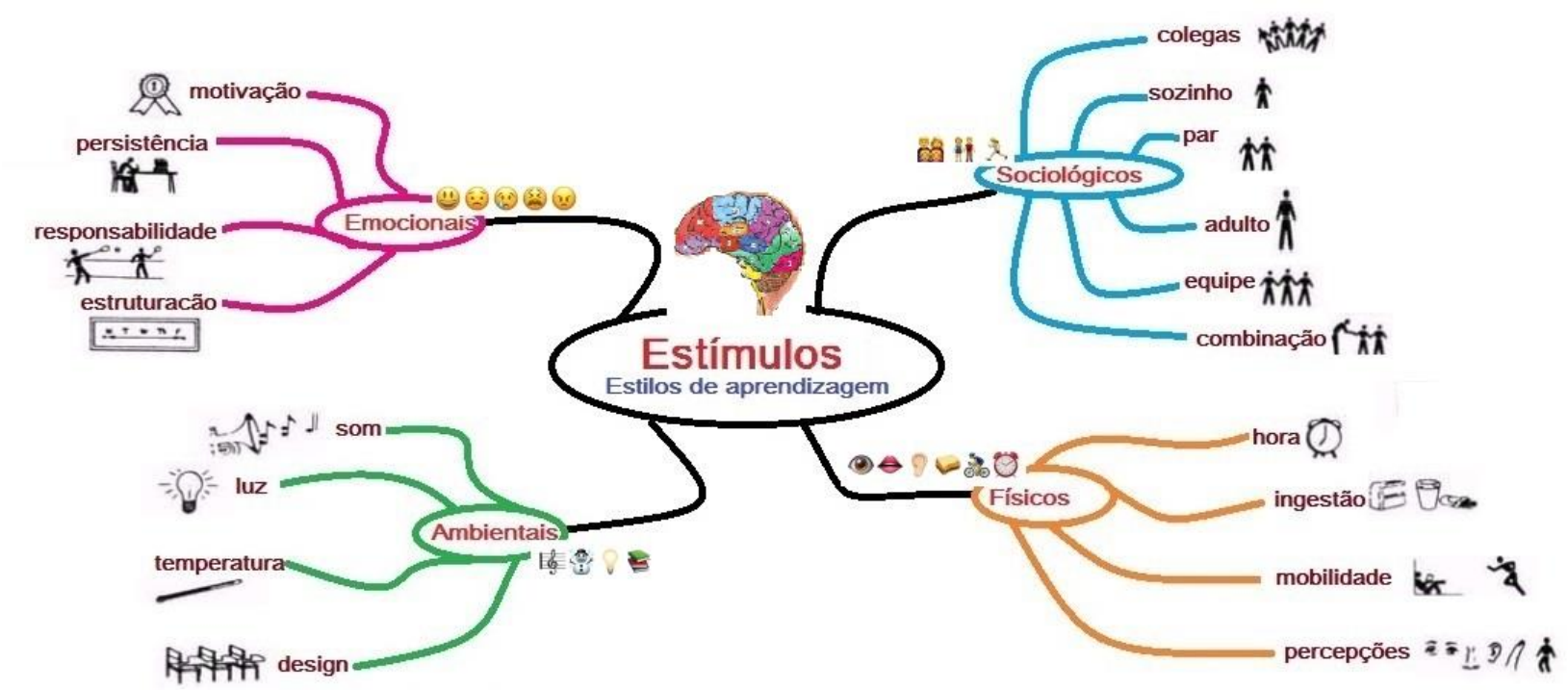

Fonte: Elaboração, adaptação e tradução própria com base em Dunn e Dunn (1979, p. 241).

Há críticas aos testes-inventários, pois eles buscam rotular as pessoas, como se todos fossem iguais, sem aceitar gradações, sem aceitar mudanças — segundo as circunstâncias, fases da vida, experiências anteriores, etc. - além do risco que isso oferece de excluir pessoas com base em uma classificação tida como simples, exata e perene que na realidade é complexa, subjetiva, imprecisa e mutável.

Uma série de estímulos interfere na aprendizagem, influenciando positiva ou negativamente. Dunn e Dunn (1979) categorizaram em quatro grupos os elementos que mais interferem nas preferências e estilos de aprendizagens: Elementos emocionais (motivação, persistência, responsabilidade e necessidade por estrutura/sistematização); Elementos sociológicos (se o indivíduo prefere trabalhar sozinho, em pares, com um adulto, ou alguma combinação disto); Elementos físicos (as fontes principais de percepção — qual sentido mais usado: visão, audição, etc.; 
ingestão — se a pessoa gosta de estar bebericando café, mastigando, etc.; tempo do dia — se prefere estudar pela manhã, à noite, etc.; necessidade de mobilidade — se prefere estar em movimento ou parado); Elementos ambientais (som, luz, temperatura, design da sala — se prefere um ambiente mais formal, mais despojado, etc.).

A teoria VARK², criada por Neil Fleming e Colleen Mills em 1992 (apud SCHMITT; DOMINGUES, 2016) para mapear os estilos de aprendizagem, tem seu nome elaborado a partir de um acrônimo em inglês com as iniciais dos canais de aprendizagem mais prevalentes para acessar a informação (visual, auditivo, leitura/escrita e cinestésico). Posteriormente, o acrônimo foi simplificado para VAK, excluindo a parte de leitura e escrita por diluírem-se pelos outros canais, em especial o visual. A referência é voltada aos canais perceptíveis, embora os indivíduos possam e utilizem todas as modalidades, muitos tendem a ter preferências/maior afinidade com modalidades específicas.

A Figura 4 traz técnicas de ensino que privilegiam cada um destes estilos de aprendizagem.

Figura 4 - Algumas técnicas/atividades baseadas nos estilos de aprendizagem VARK

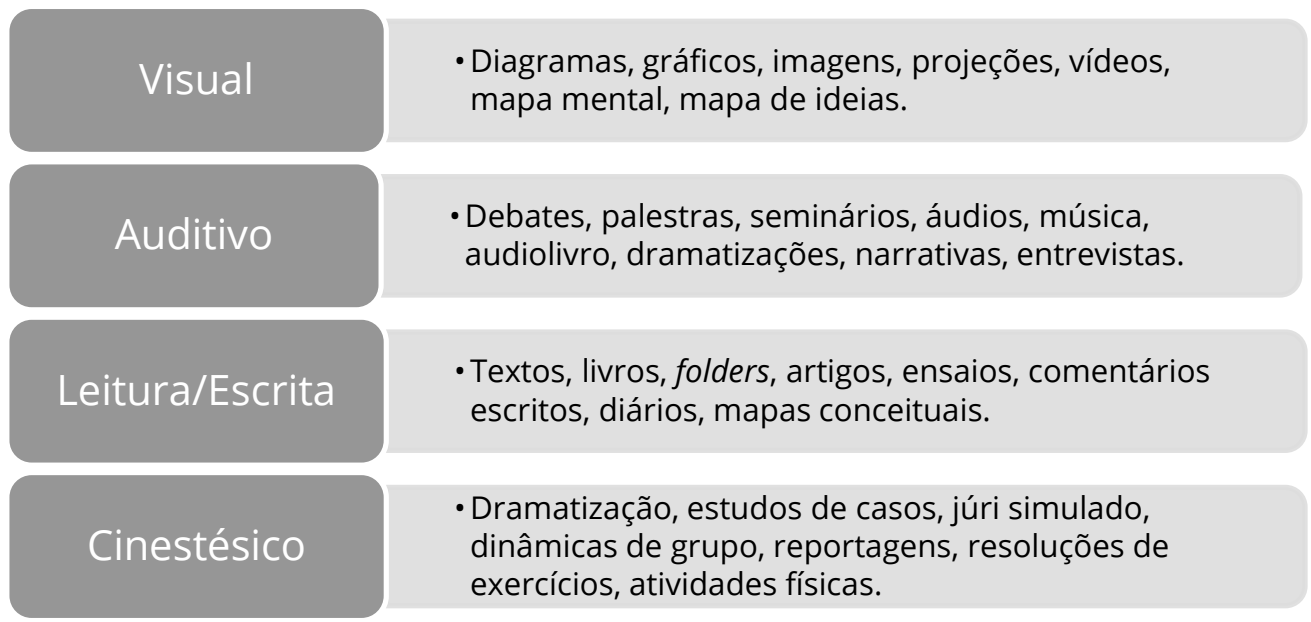

Fonte: Fleming (2001 apud SCHMITT, DOMINGUES, 2016) - adaptado.

Os estilos de aprendizagem segundo a teoria VAK, portanto, podem ser categorizados em: Visual (pessoas que aprendem melhor vendo, com demonstrações visuais e descrições, guardam rostos, mas não nomes, para saber se uma palavra está

\footnotetext{
${ }^{2}$ Acrônimo em inglês para Visual (V), Auditory (A), Reading/Writing (R) e Kinaesthetic (K).
} 
escrita corretamente escrevem-na para 'vê-la', desenham planos, se distraem facilmente com movimentos, aprendem escrevendo, são 'anotadores', escrevem esquemas e listas para memorizar); Auditivo (aprendem ouvindo, gostam de instruções faladas, estudam em voz alta, preferem discussões e diálogo, se distraem com sons); Cinestésico $^{3}$ (aprendem fazendo tarefas e em movimento, têm muita energia, gostam de usar o tato e interagem bastante, são inquietas, utilizam-se também da memória motora para aprender, lembram facilmente de gestos, posturas, coreografias, etc.).

Para arrematar este breve panorama sobre os estilos de aprendizagens, traz-se a proposta de Alonso, Gallego e Honey (2002 apud BARROS, 2008, p. 17-19). Críticas indicam que essa proposta está mais relacionada a descritor de personalidade do que descritor de maneira de aprender, sendo que os próprios autores já esclareceram que sua proposta não é um teste de personalidade. Tal estrutura teórica também se transformou em um instrumento de diagnóstico por meio de frases a serem marcadas indicando as personalidades e os estilos individuais de aprendizagem, categorizados em quatro estilos reunidos na Figura 5.

Figura 5 - Estilos de aprendizagem segundo Alonso, Gallego e Honey

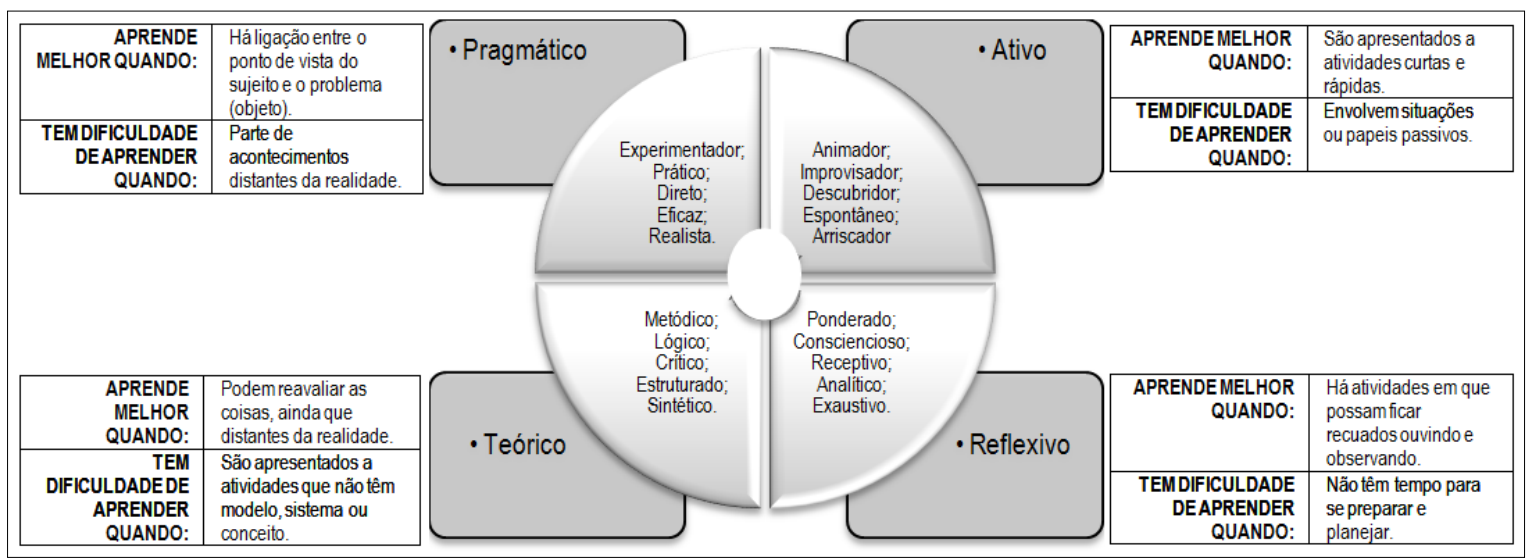

Fonte: Adaptado de Alonso, Gallego e Honey (2007, p. 90), Mumford (2001, p. 18) e Barros (2008).

O estilo Ativo (típico de pessoas que gostam de novas experiências/tarefas, que não gostam de prazos, se envolvem com o grupo e com os assuntos dos outros,

${ }^{3}$ Os dicionários de língua portuguesa admitem a palavra Cinestésico com " $\mathrm{C}$ " e com " $\mathrm{S}$ ", entretanto com significados diferentes, a saber: Cinestésico se refere a movimentos musculares e aspectos físicos; já Sinestésico se refere a percepções das relações entre as sensações. 
são conversadores, líderes, criativos, aventureiros, competitivos, participativos); o Reflexivo (típico de pessoas observadoras, prudentes, analíticas, ponderadas, detalhistas, que se distanciam, elaboram argumentos, são lentos e questionadores); o Teórico (típico aprendizado de pessoas que se adaptam e integram teses em meio à complexidade, tendem a ser perfeccionistas, enfocam problemas verticalmente, disciplinados, sintéticos, generalizadores, racionalistas e exploradores); e o Pragmático (estilo de aprendizagem típico de pessoas que aplicam na prática as ideias; são rápidas e objetivas, realistas, técnicas, concretas, organizadas, seguras de si e diretas).

Schmitt e Domingues (2016), após avaliarem várias teorias, concluem que nenhuma delas é completa e/ou capaz de alcançar toda a riqueza, complexidade e subjetividade humanas. Indicam que conhecer o perfil geral dos estilos não tem (não deve ter) como princípio rotular ninguém, pois são apenas tendências, que podem variar ao longo da vida. Ressalta-se que conhecer os estilos de aprendizagens revela uma pista no trabalho de mediação didática docente, no sentido de flexibilizar seu estilo de ensino, contemplando a maior diversidade de estilos de aprendizagem, o que contribui diretamente com a mediação cognitiva dos alunos, reforçando sua propensão a aprender.

\section{Metodologia}

Este artigo é fragmento de uma tese doutoral que vem sendo empreendida, cujo objeto de estudo é a mediação didática lúdica e tem como componente adjacente a aprendizagem significativa lúdica. É exatamente desse componente que emergem a teoria e a análise trazidas para este trabalho.

Ancora-se na abordagem paradigmática qualitativa de investigação, levando em conta objetivos de cunho interpretativo, sob os auspícios do nexo dialógico, com amparo no paradigma interacionista, em que não há sujeitos de pesquisa, mas sim colaboradores de pesquisa, assim os dados são produzidos (não coletados) em meio à interação, reconhecidamente não-neutra, mas que se cerca de cuidados contra enviezamentos (CHIZZOTTI, 2014).

Dessa maneira a natureza da pesquisa é teórico-empírica, passeando entre a teoria, inserindo-a na prática, buscando conhecê-la no seio da realidade, para então 
fechar o ciclo em que a prática retorna para ser aportada à teoria. Para a execução dos objetivos utilizou-se dos procedimentos de um estudo de caso único instrumental (STAKE, 1998). Para esse artigo fez-se uma bricolagem com inserções de relato de experiência (GAYA; GAYA, 2018), por entender que as pesquisadoras têm contributos oriundos de suas vivências em sala de aula universitária para aportar à investigação.

Por critério de facilidade de acesso, delimitou-se o estudo aos alunos (a partir do $5^{\circ}$ semestre, pois já possuem uma maior vivência universitária) do curso noturno de Ciências Contábeis de uma universidade pública estadual. Em termos de universo amostral, 127 discentes se assemelhavam aos critérios seletivos preestabelecidos, dos quais 91 participaram esclarecida e voluntariamente da pesquisa - mediante expressa autorização em termo documental submetido ao comitê de ética em pesquisa, tendo, portanto, seu anonimato assegurado.

Os colaboradores de pesquisa responderam a um questionário misto eletrônico, do qual foi extraída amostra equitativa entre os semestres e os sexos para a composição de um Grupo Focal (GF), com 10 participantes (GATTI, 2012). Esses discentes previamente sinalizaram no questionário sua disponibilidade em participar de tal atividade no turno noturno em uma terça-feira (quando havia disponibilidade de sala na instituição), assim foram atendidas conveniências de todos.

Ao aceitar o convite assinaram termo ético e, em clima de colaboração e descontração, o GF ocorreu em maio de 2018, nas dependências da instituição de ensino em que os participantes estudam, teve a duração de duas horas e quinze minutos e o áudio foi gravado e transcrito.

Mantendo o compromisso ético de privacidade aos colaboradores, usou-se a letra "Q" seguida de um número para identificar os alunos, de acordo com a ordem de resposta ao questionário, e a letra "A", seguida de número para identificar a fala no Grupo Focal. Além disso, as referências se mantêm no masculino gramatical para efeito de anonimato.

A análise dos dados produzidos ficou a cargo da Análise de conteúdo francesa (BARDIN, 2011) com categorias estabelecidas a posteriori, as quais foram: Estratégias prevalentes e estilos. 


\section{Análise das informações}

Buscou-se conhecer e mapear os elementos presentes nas estratégias discentes utilizadas para a aprendizagem dos colaboradores, os quais, generosos, não só disseram quais eram as estratégias, como também indicaram operadores que interagem com suas estratégias, fomentando mais facilidade à aprendizagem, tais como: fatores externos, locais, circunstâncias emocionais, entre outros itens, que influenciam suas táticas para aprender, as quais serão discutidas a seguir. Na Figura 66 apresentam-se as prevalências, organizadas em mapa de ideias.

Figura 6 - Estratégias prevalentes

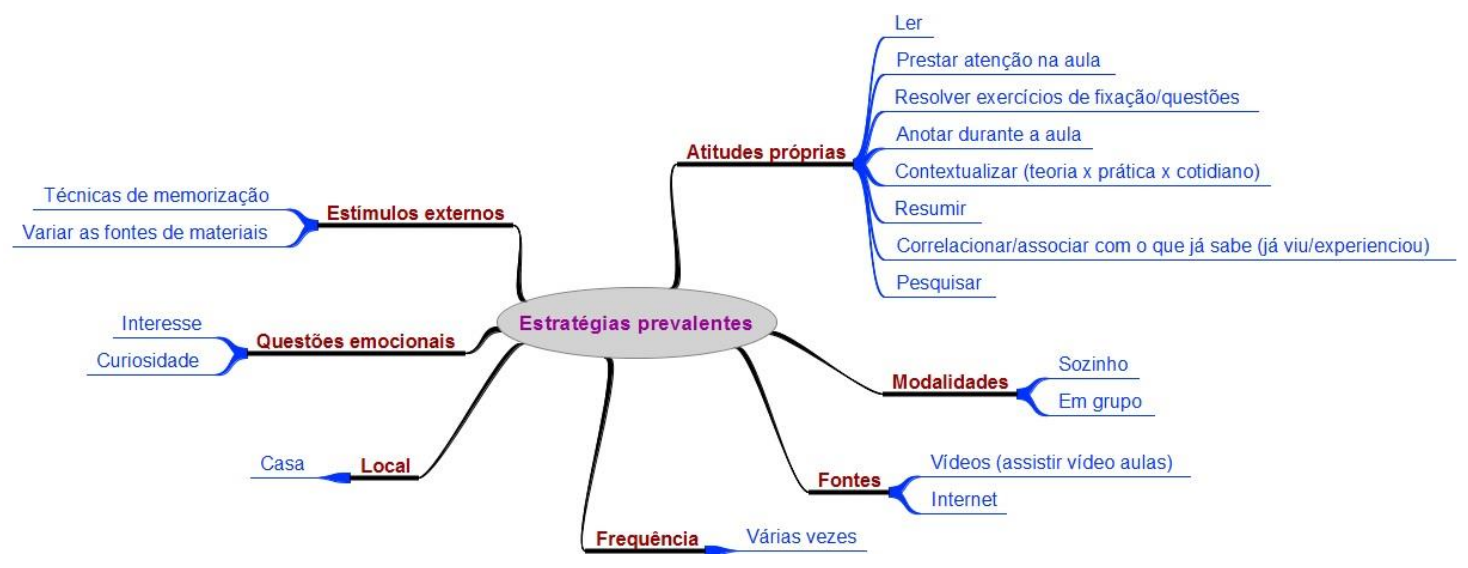

Fonte: Dados da pesquisa. Elaboração própria.

Ao escolher como estratégia de aprendizagem "ler" o aluno tem a condição de visualizar, internalizar, i.e. reconstruir internamente uma operação externa (VYGOTSKY, 2000) com muito mais minudências, no tempo e no ritmo dele. Podendo ao longo da leitura fazer marcações (coloridas ou não), comentários, contraposições de outros autores já lidos, montando um poderoso diálogo mental com o texto lido. Requer tempo tanto de leitura quanto de maturação (internalização) desta leitura. Não é um processo imediato. Utiliza camadas cerebrais mais densas (BUZAN, 2009), demanda um trabalho maior do cérebro para alocar as informações, o que favorece a ancoragem e a retenção (AUSUBEL, 2009) da informação nova. 
Apesar de que esta seja a estratégia mais prevalente $(23 \%)$ segundo os discentes, ela se contrapõe ao que a vivência docente em sala de aula mostra ao longo dos anos. Há pelo menos 5 anos, para melhor conhecer os discentes e traçar um perfil da turma, vêm sendo interpostos questionários com tom informal no início das aulas. Uma das questões é justamente sobre os hábitos de leitura, infelizmente as respostas mostram que a média de leitura é ínfima ${ }^{4}$, a grande maioria das respostas aponta a leitura de no máximo um livro por ano, o que dá suporte à ideia de que os discentes do curso não têm hábito de leitura.

Ler obriga o cérebro a produzir imagens (diferente de quando se vê um vídeo, o qual já traz as imagens prontas) essas, quando produzidas pelo indivíduo, são mais facilmente resgatadas pelo cérebro, destarte diferentes zonas cerebrais são ativadas (DAMÁSIO, 2009; BUZAN, 2009; FONSECA, 2011), um quantitativo maior de neurônios são postos em ação, consequentemente a probabilidade de compreender e reter um conhecimento é maior.

Segundo Fonseca (2011) a leitura demanda complexos processos de construções e desconstruções, categorizações fonológicas, captações visuais, inferência de significados, compreensão de nexos, decodificação, integração e sequenciação de informações, rememorização de conexões e relações narrativas, ou seja, tomada em acepção sistêmica não promove só a assimilação do conhecimento, mas também desenvolve competências de resolução de problemas. O professor, ao incentivar e requisitar leituras, além de contribuir com a aprendizagem contribui para o aprimoramento neurocognitivo do aluno.

Prestar a atenção na aula é uma estratégia eficiente quando o discente se preparou para a aula e se mantém em diálogo mental ativo, com interlocução (ainda que silenciosa) com o que é dito pelo professor. A atenção e a memória são, segundo Damásio (2009, p. 230) "necessárias ao processo de raciocínio durante o qual se comparam resultados possíveis, se estabelecem ordenações de resultados e se fazem inferências". Defende-se que o ideal é participar da aula, atitude que vai além de observar passivamente, pois demanda diálogo (interno e externo), comparações, ordenações, reiterações, diferenciação progressiva e reconciliação integradora

\footnotetext{
${ }^{4}$ Os dados não são tabulados, posto que o questionário não tem o fito de investigação sistematizada.
} 
(AUSUBEL, 2009), processos relativos ao que se sabia em função do que é trabalhado na aula, ainda que isto se dê sem verbalização discente.

O aluno Q64 apresenta uma estratégia ativa, eficiente e interessante de aprendizagem significativa: lê o material e se prepara antecipadamente para aula. Diz que: "Hoje após algumas experiências, comecei a estudar os assuntos previamente" (Q64). Demonstra maturidade, autonomia e responsabilidade com sua aprendizagem, bem como respeito e colaboração com o professor e os colegas porque preparar-se antecipadamente significa que este discente vai poder aportar contribuições relevantes para a aula, sejam elas em forma de dúvidas, ideias controversas, exemplos diversificados ou outra coisa.

Ao triangular os dados, verifica-se que infelizmente dos 91 respondentes ao questionário não surgiu nada semelhante como tática de aprendizagem. Tal estratégia de aprendizagem ativa e autônoma (participar da aula) apareceu no Grupo Focal (GF) na fala do discente A2: "Sim, quando você consegue participar [aprende melhor quando consegue participar]" (A2).

Outra estratégia de aprendizagem que apareceu foi "Resolver exercícios". Estes, quando são criativos, têm um efeito positivo de problematizar e desafiar o aluno a testar o que está sendo aprendido. Entretanto, há exercícios de mera memorização, que não levam o discente a confrontar o que aprendeu, simplesmente deve repetir, conforme o modelo dado (é o que acontece em muitos destes exercícios), sem contestá-lo. "Não cabe ver o exercício como uma simples memória. O exercício cria antes uma predisposição para a melhor realização de alguma ação" (VYGOTSKY, 2018, p. 366). A alternativa é que estes exercícios, quando propostos pelo professor, desafiem cognitivamente o aluno (AUSUBEL, 2009), potencializem ludicidade e reflexões, sem automatismos, tornando esta tática ainda mais eficaz, porque "O exercício só é plenamente bem sucedido quando acompanhado de uma satisfação interior" (VYGOTSKY, 2018, p. 375).

Anotar durante a aula é uma estratégia de aprendizagem de pessoas com estilo de aprendizagem visual, conforme Dunn e Dunn (1979) e Schmit e Domingues (2016), que pode ser enriquecida por desenhos, cores — um dos elementos mais poderosos "para intensificar "a criatividade e a memória visual” (BUZAN, 2009, p. 35) e codificações diversas. Entretanto, até para anotar é necessário empregar 
"rigorosidade metódica" (termo cunhado por Freire (2004)), pois "anotações rabiscadas confundem a memória e atrapalham o entendimento, o que inibe a habilidade que o cérebro tem de fazer associações” (BUZAN, 2009, p. 41). Quantas vezes ao se deparar com uma anotação rabiscada por si mesmo, não se pergunta: “o que era mesmo isso aqui?!”. Inútil e frustrante.

Os alunos dizerem que "Estudam/Leem" não significa que eles estão buscando material denso e acadêmico, na maior parte das vezes isto se resume à leitura das anotações que fizeram ao longo das aulas (Ou pior, na Educação Superior é comum, a mera leitura do "resumo da síntese" presente nos slides do docente, enviados digitalmente ou fotografados). Isto, que deixa a aprendizagem acadêmica rasa e sem profundidade teórica, visto que não há leituras de amplitude em textos e diversos autores.

Seja por preguiça, desconhecimento, real falta de tempo, ideias equivocadas de aligeiramento acadêmico (bem ao gosto do "líquido mundo mercadológico"), o fato é que estudar somente por anotação da aula não dá o suporte necessário nem o aprofundamento necessário a um futuro profissional competente em sua área de conhecimentos.

Sobre a estratégia de "Resumir" a partir de uma leitura e/ou assistir uma aula e resumir seu conteúdo são estratégias interessantes, não só para aprender, mas também para desenvolver o poder de síntese. Entretanto, o que se tem como experiência na prática docente na Educação Superior é que muitas vezes ao solicitar um resumo de um texto de 4 páginas, recebe-se um resumo com 5 laudas. Empiricamente, ao longo da carreira docente tem-se diagnosticado que as habilidades de síntese (e o contrário — de análise — também) não estão presentes no repertório da maioria dos estudantes, os quais se mostram incapazes de identificar os elementos mais importantes de um texto, de uma aula, de uma conversa.

Ao contador é demandado em sua prática profissional sintetizar e analisar muitas informações contábeis. Acredita-se que se essas habilidades vierem se conformando em estratégias de aprendizagem congruentes, com os variados estilos subjetivos de aprendizagem ao longo de sua vida acadêmica, o aluno/futuro profissional contará com melhores condições para atuar assertivamente na sociedade. 
No grupo focal, o discente A2, ao se referir a estratégias de aprendizagem disse: “[...] A nossa maneira de interpretar e de entender os conteúdos e aplicar também deveriam acompanhar as mudanças da sociedade [...]"(A2). Aporta que contextualização — seja de mudanças, seja de aplicabilidade — de conteúdos é elemento chave para melhor compreender e interpretar o que se aprende.

A estratégia de "Contextualizar e correlacionar o objeto" de aprendizagem, sua teoria, com a vivência prática é uma poderosa e ativa estratégia. Segundo Buzan (2009, p. 40) associações são o "segundo fator mais importante para melhorarmos a memória e a criatividade [...]" é por meio delas que "tomamos conhecimento da experiência física da vida". É uma estratégia que envolve corpo e mente de forma construtiva e interativa (VALADARES; MOREIRA, 2009; POZO, 2006) e que assume o aprendente como um ser humano transdimensional - objetivo e subjetivo. Associando variados estilos de aprendizagem, em acordo com as diversas teorias, a exemplo da VAK, contemplando aptidões visuais, auditivas e cinestésicas (DUNN, DUNN, 1979; FLEMING, 2001 apud SCHMITT; DOMINGUES, 2016).

Tal associação tem também o fito de transpor o que é aprendido para outras situações ou realidades. É o que Ausubel (2009) chama de não-linearidade — característica basilar da Aprendizagem Significativa (AS). O suposto das correlações entre teoria e prática e das associações contextuais apoia sobremaneira a Teoria da Aprendizagem Significativa (TAS) de Ausubel. Cuja defesa é mais evidenciada em meio aos desafios cognitivos e na busca por significados que unam o objeto de estudo à estrutura cognitiva do sujeito, bem como, em meio à busca por princípios, correlações e organizações.

Triangulando informações sobre o aprendizado mediante associações e correlações contextuais e da teoria com a prática, interpôs-se no questionário a assertiva "Não consigo aprender coisas desarticuladas do contexto real" para julgamento por meio da escala Likert. Os resultados, reunidos no

Gráfico 1, apontam muita dispersão nas respostas, uma indiferença relativa (14\%), com tendência à discordância (20\%), mas um pico de concordância da ordem de $22 \%$. Por esta contradição entre concordância e discordância, buscou-se a 
média dos valores $(2,49$ - a qual revela discordância), entretanto a moda foi o valor 4 (concordância), mantendo a contradição numérica.

\section{Gráfico 1 - Aprendizagem contextualizada}

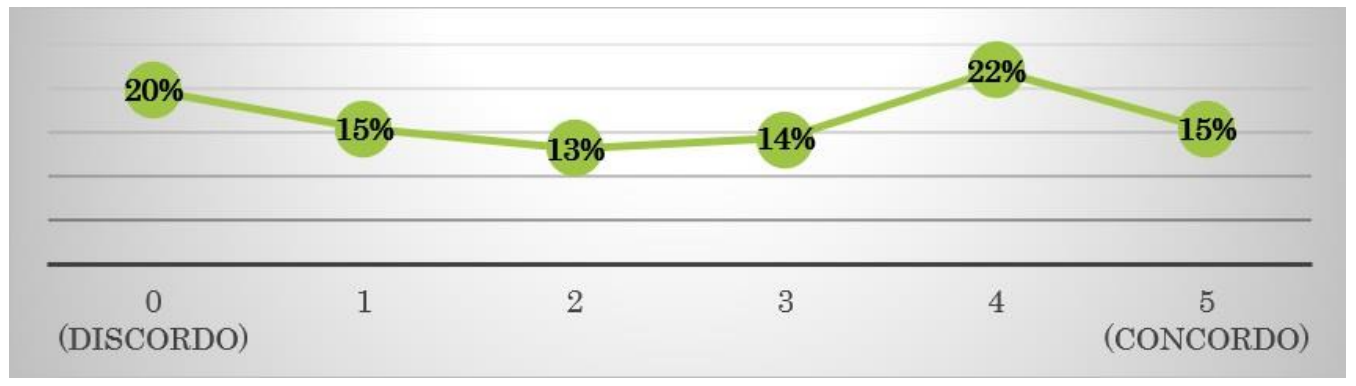

Fonte: Dados da pesquisa. Elaboração própria.

Sendo, pois, necessária a interpretação qualitativa: as oscilações e aparente contradição levam a crer que o fato de o assunto em tela estar desarticulado do real, não impede os alunos de aprender (como sugere a frase), porém dificulta esta aprendizagem. Demandando um esforço e variadas estratégias de aprendizagem, as quais conforme o estilo de aprendizagem segundo o processamento da informação implicará em atitudes mais reflexivas ou ativas (cf. Figura 2), oscilando conforme a personalidade subjetiva para perceber a informação que lhe é ofertada sem contextualização, tendendo, pois a uma conceituação abstrata (KOLB; KOLB, 2005).

"Pesquisar" é uma estratégia ativa e importante para o meio acadêmico universitário, posto que dá conta de toda uma metodologia científica para levantar material, lê-lo, fichá-lo, resumi-lo, categorizá-lo, contrapô-lo e interpretá-lo. A pergunta que fica no ar é: será que ao dizer que empreendem pesquisas como estratégia de estudos, os discentes realmente as fazem com métodos, ou se restringem a uma simples busca na internet seguida de leitura do texto mais curto e simplista (raso, sem embasamento teórico adequado ao nível universitário)? Aligeirando informações e distanciando conhecimentos...?

As falas tanto do questionário quanto no grupo focal dão a entender que essa pesquisa se trata de uma mera busca eletrônica, mas não de textos acadêmicos, e sim de vídeos. O que evoca uma série de reflexões para os benefícios e os malefícios deste elemento. Para os alunos que têm o canal de aprendizagem auditiva e/ou visual, além do estilo assimilador (quadrante que funde o processamento 
informacional por observação reflexiva e a percepção por conceituação abstrata — cf. Figura 2), esta é uma estratégia de aprendizagem interessante, útil como reforço para o que já foi trabalhado ou como ampliador do conteúdo em estudo.

Entretanto, há que se saber selecionar de forma crítica o que assistir, pois existem inúmeros vídeos com informações distorcidas, erradas e ou sem embasamento científico-acadêmico, ou seja, cujo conteúdo é questionável (com erros grosseiros, contradições teórico-práticas dignas de amadores) e acabam por ser um desserviço à aprendizagem do discente.

Além disso, o indivíduo com estilo acomodador (mescla entre o estilo de percepção pela experiência concreta com o processamento informacional pela experimentação ativa, segundo Kolb e Kolb (2005)), bem como, os indivíduos de aprendizagem cinestésica não encontram grande ressonância de eficiência nesta estratégia que pode parecer "ativa" à primeira vista por mostrar em algumas circunstâncias o "ator" do vídeo agindo, porém o aprendente mantém-se em aparente inércia/sem movimentos e/ou atuação concreta.

O discente Q20 relatou que procura ampliar sua estrutura cognitiva ao buscar entender como o assunto funciona e sua lógica (um estilo assimilador, conforme Kolb (1984)), com o intuito de assimilar o conteúdo, ao invés da técnica simplista de memorizar sem que seja atrelado nenhum significado, mais típica no estilo divergente. Ele dá mostras de buscar estratégias para aprender significativamente ao dizer: “Tento entender a lógica daquele conteúdo para assimilar melhor e conseguir lembrar depois" (Q20).

A lembrança e a memorização são fruto do entendimento e não do simples e mecânico ato de decorar, seja por técnicas mnemônicas, seja por repetições. Ausubel (2009, p. 32, tradução nossa) diz que é necessário "algum grau de conciliação com ideias já existentes na estrutura cognitiva" da pessoa que aprende para a aprendizagem ser significativa.

O discente Q49 expõe seu estilo auditivo de aprendizagem e sua preferência de estímulos sociológicos por estudar sozinho ao dizer que suas estratégias de aprendizagens resumem-se a em casa, sozinho, ouvir áudios das aulas: "Estudo em casa, tenho um facilidade maior em estudar sozinho ouvindo áudios que gravo em sala” (Q49). Ressaltase a questão ética de direitos e deveres, alertando-se que o docente deve ficar atento às 
gravações de áudios de suas aulas (não se sabe e nem se pode ter certeza do uso que tal material vai ter no momento e no futuro), devendo previamente autorizar, ou não, sua gravação. Trata-se de um resguardo ético de um direito autoral, que se estende à imagem, direito constitucionalmente assegurado ao cidadão.

Há falas que relatam o uso de estratégias de memorização sem, contudo, exemplificá-las. Os colaboradores aduzem a ressalva de que costumam diversificar as fontes de materiais, o que em si, se realizado da forma adequada, já enriquece o processo de aprendizagem.

Em termos de preferências subjetivas para a aprendizagem, há os que preferem estudar sozinhos, há os que preferem estudar em grupo. Houve falas no sentido de que esta escolha depende do que se está estudando, se é algo mais teórico ou que exija mais cálculos, evidenciando, assim, os estímulos sociológicos de aprendizagem (DUNN; DUNN, 1979) associados a variáveis contextuais.

Neste sentido, a fala de Q89 dá conta de um aspecto sócio emocional: “[...] o que mais me ajuda é o grupo de estudos que temos na sala" (Q89). Depreende-se que a interação social e os vínculos emocionais que os colegas criam nas aulas os auxiliam sobremaneira na aprendizagem, reforçando as ideias de Vygotsky (2000) de que um colega, um par pode mediar a aprendizagem de quem chegou à zona potencial de desenvolvimento, além disso, eles mutuamente se estimulam (SCHWARTZ, 2014) a continuar aprendendo e vencer as eventuais dificuldades. Segundo García, Ortiz e Rodríguez (2019) o aluno universitário orbita suas motivações em torno de: uma boa nota, sua relação com o professor e o conteúdo dos componentes curriculares.

A atitude aprendente — elemento fundamental da TAS e decisivo para a aprendizagem significativa — requer interesse, vontade de aprender, o "querer aprender" que em muitos casos é fruto da curiosidade. Esta deve, sempre que possível, ser estimulada pelo Mediador Didático Lúdico (professor que alicerça seu fazer na ludicidade, na inteireza entre cognição e sensibilidade) por meio de enigmas, metáforas lúdicas, qui ž ${ }^{5}$, quebra-cabeças, etc. São várias as possibilidades para ativar os desafios cognitivos e estimular a curiosidade — típica no estilo ativo

\footnotetext{
${ }^{5}$ Quiz é o nome de um jogo (eletrônico ou não) de questionários com intuito de avaliar conhecimentos de um assunto.
} 
de aprendizagem (ALONSO; GALLEGO; HONEY, 2007). Além de despertar a curiosidade, podem ainda funcionar como poderoso organizador prévio (AUSUBEL, 2009).

O local de estudo prevalente foi o estudo em casa, em outras palavras, o estímulo ambiental (DUNN; DUNN, 1979) de trato mais familiar e informal. Chamou a atenção que a biblioteca não tenha merecido nenhuma menção, talvez o fato do curso ser noturno e de que os discentes trabalhem em meio período ou tempo integral (conforme os dados do questionário eletrônico misto apontaram) os faça optar por estudar em casa, assim podem conciliar família e estudo, ou talvez isto resida no fato da maioria das bibliotecas universitárias brasileiras estarem sendo paulatinamente sucateadas, precarizadas e preteridas em detrimento de alocação de escassos recursos financeiros que precisam minorar problemas mais emergenciais... (eis apenas uma conjectura).

Sutilmente, ao longo das falas sobre como estudam, sobre as estratégias, depreensões sobre estilos e sobre as diferenças entre a aprendizagem infantil e adulta, aparecia a locução adverbial "várias vezes", levando a investigação a inferir que o elemento repetição é importante para o aluno adulto, no sentido de estimular sua memorização, fixação e internalização. Para Ausubel (2009) a frequência não é um requisito necessário, nem suficiente para a Aprendizagem Significativa (AS), entretanto, a frequência é uma variável a ser considerada quando se trata de conteúdo difícil, com especificidades que demandam "retenção prolongada e quando é necessária a capacidade de transferência” (AUSUBEL, 2009, p. 48, tradução nossa).

Conjectura-se que os alunos não têm o hábito (e/ou não são estimulados pela mediação didática) de buscar a aprendizagem significativa, mas sim a aprendizagem mecânica e memorista. Esta, demanda modelos, repetições infinitas para memorizar sem que se acesse o campo dos significados, das relações lógicas, da compreensão. O sujeito não age, apenas reage, não há esforço em pensar, mas sim esforço em decorar e a implicação afetiva é quase inexistente (POZO, 2006).

E provavelmente em função da lógica conteudista e transmissional encontrada no Ensino Superior brasileiro (D'ÁVILA; FERREIRA, 2018) que demanda rendimentos numéricos, os estudantes recorrem aos mecanismos 
(memorísticos ou significativos) visando tão somente o "rendimento acadêmico" em termos quantitativos — atendendo à lógica competitiva de mercado. "Esta obsessão não é gratuita e é propiciada pelo sistema educativo e quem o integra" (VÁSQUEZ, 2013 apud GARCÍA; ORTIZ; RODRÍGUEZ, 2019, p. 182, tradução nossa).

Cabe aqui a ressalva de que a aprendizagem memorista e a aprendizagem significativa não são dicotômicas e que podem coexistir em um "contínuo memorista-significativo" (AUSUBEL, 2009, p. 31, tradução nossa). Mas, é papel do aluno autônomo e do mediador didático lúdico estar cientes de suas potencialidades e limitações, buscando superação de condições acríticas, quaisquer que sejam.

Defende-se a adoção de várias estratégias de aprendizagem simultaneamente e "é mais aceitável aplicar alternadamente todos os meios de memorização" (VYGOTSKY, 2018, p. 189) e aprendizagem. Sempre que possível o docente pode inclusive buscar favorecer com algumas destas técnicas, usando-as nas aulas, de modo a permitir que todos façam uso delas (pelo menos tenham um contato com elas), visto que "é útil ao professor identificar o tipo individual [...] e recorrer mais amiúde precisamente a este tipo" (VYGOTSKY, 2018, p.189). Além disso, fomenta mais possibilidades de estilos aos discentes (RODRÍGUEZ, 2008).

Acrescenta-se que é valioso também reconhecer o tipo de estímulo (emocionais; sociológicos; físicos e ambientais — segundo Dunn e Dunn (1979)) e o canal de aprendizagem (visual; auditivo e cinestésico — de acordo com Fleming (2001 apud SCHMITT; DOMINGUES, 2016)) mais prevalente nos alunos para poder recorrer a eles. A6 no grupo focal explicita que "a gente aprende muito pelo visual, né?! Então acho que é uma coisa que agrega mais" (A.6) ao falar sobre suas preferências de aprendizagens. As preferências remetem "aos gostos e às possibilidades de escolha entre várias opções" (RODRÍGUEZ, 2008, p. 15, tradução nossa) sendo uma atitude consciente determinada e controlada pelo sujeito.

Relatando experiências vividas no Ensino Superior, a prática vem mostrando que muitas vezes os alunos não usam várias (e/ou não diversificam) estratégias porque não as conhecem. Se isto for diagnosticado pelo professor, o processo ensino e aprendizagem tem muito a ganhar com a rápida atitude de demonstrar algumas estratégias no início da unidade temática, ou na ocasião que se mostrar propícia. Algo assinalado pelos discentes em outra etapa da produção de dados foi a 
falta de alfabetização acadêmica (CARLINO, 2017), ou seja, infelizmente, os alunos têm chegado à universidade sem uma série de elementos necessários à vida acadêmica: um deles é a habilidade estratégica de estudar.

Quadro 1 - Sumário geral

\begin{tabular}{|c|c|}
\hline Objetivos & O que foi alcançado \\
\hline \multicolumn{2}{|l|}{ Geral: } \\
\hline $\begin{array}{l}\text { Analisar } \\
\text { compreensivamente as } \\
\text { estratégias de } \\
\text { aprendizagem referidas por } \\
\text { discentes de um curso de } \\
\text { Ciências Contábeis, em } \\
\text { uma Universidade pública } \\
\text { na Bahia, inferindo sobre } \\
\text { seus estilos de } \\
\text { aprendizagem } \\
\text { preferenciais }\end{array}$ & $\begin{array}{l}\text { As estratégias de aprendizagem congruentes com os variados } \\
\text { estilos subjetivos de aprendizagem são variáveis ao longo da vida } \\
\text { acadêmica, bem como, variam conforme elementos contextuais } \\
\text { infere-se que seu manejo favorece a que o aluno/futuro } \\
\text { profissional conte com melhores condições para aprender e } \\
\text { futuramente atuar assertivamente na sociedade; inferiu-se ainda } \\
\text { sobre a importância da atitude aprendente e do estímulo } \\
\text { ambiental desvelando no fundo um aspecto sócio emocional } \\
\text { como influenciadores importantes na aprendizagem, seus estilos } \\
\text { e suas preferências. }\end{array}$ \\
\hline \multicolumn{2}{|l|}{ Específicos: } \\
\hline $\begin{array}{l}\text { Levantar as estratégias de } \\
\text { aprendizagens prevalentes; }\end{array}$ & $\begin{array}{l}\text { As estratégias prevalentes levantadas, mescladas a operadores } \\
\text { que facilitam suas aprendizagens foram agrupados em: Atitudes } \\
\text { próprias (Ler; Prestar atenção na aula; Resolver exercícios de } \\
\text { fixação/questões; Anotar durante a aula; Resumir; Contextualizar } \\
\text { (teoria x prática x cotidiano); Correlacionar/associar com o que já } \\
\text { sabe (já viu/experienciou); Pesquisar); Estímulos externos (Técnicas } \\
\text { de memorização; Variar as fontes de materiais); Modalidades ( Em } \\
\text { grupo; Sozinho); Questões emocionais ( Interesse; Curiosidade); } \\
\text { Fontes ( Vídeos (assistir vídeo aulas); Internet); Local (Casa); } \\
\text { Frequência (Várias vezes). }\end{array}$ \\
\hline $\begin{array}{l}\text { Inferir sobre os estilos de } \\
\text { aprendizagem prevalentes } \\
\text { dos alunos. }\end{array}$ & $\begin{array}{l}\text { Para os alunos que têm o canal aprendizagem auditiva e/ou } \\
\text { visual, além do estilo assimilador, (quadrante que funde o } \\
\text { processamento informacional por observação reflexiva e a } \\
\text { percepção por conceituação abstrata), a pesquisa por vídeos é } \\
\text { uma estratégia de aprendizagem interessante e útil; Entretanto, } \\
\text { ela não alcança com a mesma eficiência indivíduos com o estilo } \\
\text { de aprendizagem acomodador (mescla entre o estilo de } \\
\text { percepção pela experiência concreta com o processamento } \\
\text { informacional pela experimentação ativa, tampouco, ajusta-se } \\
\text { aos indivíduos de aprendizagem cinestésica; os indivíduos (raros } \\
\text { na pesquisa) que procuram ampliar sua estrutura cognitiva } \\
\text { correlacionando assimilativamente o assunto e sua lógica } \\
\text { possuem forte traço do estilo assimilador, já os indivíduos que } \\
\text { buscam técnicas simplistas de memorizar sem atrelar } \\
\text { significados, possuem mais traços do estilo divergente; houve } \\
\text { indivíduos com estilo auditivo de aprendizagem; foram } \\
\text { levantadas ainda preferências de estímulos sociológicos, } \\
\text { alternando entre estudar sozinho ou em grupo. }\end{array}$ \\
\hline
\end{tabular}

Fonte: Concepção e elaboração própria.

A seguir são apresentadas as considerações finais, acreditando-se ter atendido às proposições investigativas, reconhecidamente sem poder de generalização, 
entretanto, contenta-se em aportar vias de compreensões sobre as relações dos estilos de aprendizagem e as estratégias empreendidas para este intuito no ambiente universitário, talvez, assim colaborando com um caminho entre os diversos que existem.

\section{Considerações finais}

Partindo da ideia de que o conhecimento sobre o processo de aprendizagem dos estudantes, suas subjetividades para captar, processar e utilizar as informações, conformam diferentes estratégias e diferentes estilos de aprendizagem e potencialmente auxiliam o docente a aprimorar sua mediação didática, em especial na Educação Superior, este artigo teve como objetivo geral: Analisar compreensivamente as estratégias de aprendizagem referidas por discentes de um curso de Ciências Contábeis, em uma Universidade pública na Babia, inferindo sobre seus estilos de aprendizagem preferenciais. E como objetivos específicos: levantar as estratégias de aprendizagens prevalentes; e inferir sobre os estilos de aprendizagem prevalentes dos alunos.

Buscou-se inicialmente delimitar teoricamente o material teórico coerente e que aportasse embasamento para a construção do artigo, ora em arremate. Com o critério de trabalhar uma literatura que estabelecesse uma relação mais coesa com a aprendizagem de adultos, tratou-se sobre a teoria da aprendizagem pela experiência e os estilos de aprendizagem, sobre os estímulos de aprendizagem, a teoria VARK/ VAK, bem como a tentativa de síntese nos estilos de aprendizagem segundo Alonso, Gallego e Honey (2007). Verificou-se que os estudos nessa área são profícuos e demandam criticidade para depurá-los de eventuais nuanças behavioristas, classificatórias e/ou excludentes.

Metodologicamente fez-se uma pesquisa qualitativa, interpretativa. Tratou-se de uma bricolagem entre um estudo de caso único instrumental e relato de experiência, delimitada a uma universidade pública estadual. Interpôs-se aos discentes um questionário misto eletrônico e grupo focal, e os dados produzidos foram analisados pela análise de conteúdo francesa.

As estratégias prevalentes e os operadores, que facilitam aprendizagens, levantados foram agrupados em: Atitudes próprias; Estímulos externos; 
Modalidades; Questões emocionais; Fontes; Local; Frequência. Acredita-se que se estratégias de aprendizagem estiverem congruentes com os variados estilos subjetivos de aprendizagem ao longo de sua vida acadêmica, o aluno/futuro profissional contará com melhores condições para atuar assertivamente na sociedade. Depreendeu-se, ainda, a importância da atitude aprendente e do estímulo ambiental desvelando no fundo um aspecto sócio emocional como influenciadores importantes na aprendizagem, seus estilos e suas preferências.

Apresentaram-se trechos tanto teóricos quanto analíticos em que houve relativa dificuldade para selecionar itens coesos, representativos e que dessem conta da proposta do artigo. Sugere-se que os vários testes-inventários possam ser aplicados aos estudantes, bem como que se proponha um grupo focal após o levantamento dos estilos de aprendizagem para que os próprios alunos possam fazer inferências sobre suas estratégias prevalentes e a coerência entre eles, seus estilos e o que é empregado pelos docentes em suas mediações didáticas.

Ainda que este trabalho tenha alcançado seus objetivos, ele é apenas uma faceta mínima nos conhecimentos sobre os estilos de aprendizagem, os quais são muito importantes porque, parafraseando a analogia inicial deste trabalho, conhecêlos traduz muito sobre o discente e suas subjetividades nas relações de ensino e aprendizagem, destarte propicia ao professor caminhos confiáveis para realizar ressignificadamente sua mediação didática.

\section{Referências}

ALONSO, C. M.; GALLEGO, D. J.; HONEY, P. Los estilos de aprendiraje: procedimientos de diagnóstico y mejora. 7. ed. Bilbao: Ediciones Mensajero, 2007. Disponível em: <https://www.researchgate.net/publication/311452891_Los_Estilos_de_Aprendizaje_Pro cedimientos_de_diagnostico_y_mejora> Acesso em 01 fev. 2019.

AUSUBEL, D. P. Adquisición y retención del conocimiento: Una perspectiva cognitiva. Cognición y desarrollo humano. Barcelona: Paidós, 2009.

BARDIN, L. Análise de conteúdo. Ed. Revista e Ampliada. São Paulo: Edições 70, 2011.

BARROS, D. M. V. A teoria dos estilos de aprendizagem: convergência com as tecnologias digitais. Revista SER: Saber, Educação e Reflexão, Agudos/SP, v. 1, n. 2, p. 14-28, jul./dez. 2008.

BUZAN, T. Mapas Mentais: métodos criativos para estimular o raciocínio e usar ao máximo o potencial do seu cérebro. Rio de Janeiro: Sextante, 2009. 
CARLINO, P. Escrever, ler e aprender na universidade: uma introdução à alfabetização acadêmica. Petrópolis: Vozes, 2017.

CASTRO, L. E. Los Estilos de Aprendiraje. Lima: Empresa Editora El Comercio, 2007. (Serie Nuevos paradigmas educativos. Fascículo 7).

CHIZZOTTI, A. Pesquisa qualitativa em ciências humanas e sociais. 6. ed. Petrópolis: Vozes, 2014.

D'ÁVILA, C. Decifra-me ou te devorarei: o que pode o professor frente ao livro didático? 2. ed. Salvador: EDUFBA, 2013.

D'ÁVILA, C.; FERREIRA, L. G. Concepções pedagógicas na Educação Superior: abordagens de ontem e de hoje. In: D'ÁVILA, C.; MADEIRA, A. V. (Orgs.). Ateliê didático: uma abordagem criativa na formação continuada de docentes universitários. Salvador: Edufba, 2018.

DAMÁSIO, A. R. O erro de Descartes: emoção, razão e o cérebro humano. 2. ed. São Paulo: Companhia das Letras, 2009.

DUNN, R. S.; DUNN, K. J. Learning styles/teaching styles: should they... Can they... be matched? Educational Leadership, p. 238-244, jan, 1979.

FLEMING, N. D.; MILLS, C. Not Another Inventory, Rather a Catalyst for Reflection. To Improve The Academy. [s.i.], p. 137-154. 1992. Disponível em: $<$ https: / / digitalcommons.unl.edu/cgi/viewcontent.cgi?article=1245\&context=podimprov eacad>. Acesso em 01 de fev. 2019.

FONSECA, V. da. Cognição, neuropsicologia e aprendizagem: Abordagem neuropsicológica e psicopedagógica. 5. ed. Petrópolis: Vozes, 2011.

FREIRE, P. Pedagogia da autonomia: Saberes necessários à prática educativa. 29. ed. São Paulo: Paz e Terra, 2004.

GARCÍA, L. I. R.; ORTIZ, J. F. Z.; RODRÍGUEZ, A. L. La relación entre los estilos de aprendizaje de los estudiantes y los estilos de enseñanza del profesor en un grupo de alumnos de primer semestre del nivel universitario. Journal Of Learning Styles, v. 9, n. 17, p.174-205, 2019.

GAT'TI, B. A. O Grupo Focal na pesquisa em Ciências Sociais e Humanas. Brasília: Liber Livro, 2012.

GAYA, A. C. A.; GAYA, A. R. Relato de Experiência: Roteiros de elaboração de trabalhos de conclusão de cursos de licenciatura. Curitiba: CRV, 2018.

JERICÓ, P. Os quatro estilos de aprendizagem: ou por que alguns leem os manuais e outros não. El Pais. Madrid, Outubro de 2016. Disponível em: <https://brasil.elpais.com/brasil/2016/10/10/ciencia/1476119828_530014.html>.

Acesso em: 01 fev. 2019.

KOLB, A. Y.; KOLB, D. A. The Kolb Learning Style Inventory - Version 3.1. 2005. Disponível em: $<$ http://www.whitewater-rescue.com/support/pagepics/lsitechmanual.pdf $>$. Acesso em: 1 fev. 2019.

KOLB, D. A. Experiential learning: Experience as the source of learning and development. New Jersey: Prentice-Hall, 1984. 
KOLB, D. A.; RUBIN, I. M.; MCINTYRE, J. M. Psicologia Organizacional: uma abordagem vivencial. São Paulo: Atlas, 1978.

MUMFORD, A. Aprendendo a aprender. São Paulo: Nobel, 2001.

PORTILHO, E. M. L. Evaluación de los estilos de aprendizaje y metacognición en estudiantes universitarios. Rev. Psicopedagogia, [s.l.], v. 67, n. 22, p.14-25. 2005.

POZO, J. I. Teorias cognitivas del aprendizaje. 9. ed. Madrid: Morata, 2006.

RODRÍGUEZ, A. L. Estilos de aprendiraje y enseñanza: un panorama de la estilística educativa. Distrito Federal, México: Trillas, 2008.

SCHMITT, C. da S.; DOMINGUES, M. J. C. de S. Estilos de aprendizagem: um estudo comparativo. Avaliação, Campinas/SP. v. 21, n. 2. p. 361-385, jul. 2016.

SCHWARTZ, S. Motivação para ensinar e aprender: Teoria e prática. Petrópolis: Vozes, 2014.

STAKE, R. E. Investigación con estudio de casos. Madrid: Ediciones Morata, 1998.

VALADARES, J. A.; MOREIRA, M. A. A teoria da aprendizagem significativa: Sua Fundamentação e implementação. Coimbra: Edições Almedina, 2009.

VYGOTSKY, L. S. A formação social da mente. São Paulo: Martins Fontes, 2000.

VYGOTSKY, L. S. Psicologia pedagógica. 3 ed. São Paulo: Martins Fontes, 2018.

RECEBIDO: $29 / 11 / 2019$

APROVADO: $20 / 02 / 2020$

RECEIVED: $11 / 29 / 2019$

APPROVED: 02/20/2020

RECIBIDO: 29/11/2019

APROBADO: 20/02/2020 